\title{
Phosphating Depositions for Equipment's Used in Explosive Atmospheres
}

\author{
Diana-Petronela Burduhos -Nergis ${ }^{1}$, Adrian-Marius Jurca ${ }^{2}$, Catalin-Mihai Popa ${ }^{2}$, Ramona \\ Cimpoesu ${ }^{1}$, Doru-Costin Darabont ${ }^{3}$ and Costica Bejinariu ${ }^{1, *}$ \\ 1"Gheorghe Asachi" Technical University of Iasi, 67 Dimitrie Mangeron Blv., Iasi 700050, Romania \\ ${ }^{2}$ National Institute for Research and Development in Mine Safety and Protection to Explosion - \\ INSEMEX Petrosani, 32-34 G-ral Vasile Milea Str., Petrosani 332047, Romania \\ 3"Alexandru Darabont" National Research and Development Institute of Occupational Safety - \\ INCDPM "Alexandru Darabont" Bucuresti, 35A Ghencea Blv., Bucharest 061692, Romania
}

\begin{abstract}
According to the ATEX directive, any personal protective equipment or work equipment intended to be used in a potentially explosive area must be made of materials that cannot be the source of mechanical or static electricity-related sparks. The carbon steel is one of the most widely used metallic materials, but the possibility of using it in the manufacture of equipment used in explosive environments is low. Therefore, the purpose of this article is to present an alternative solution to use metal equipment in potentially explosive atmospheres, by depositing a phosphate layer on the surface of the carbon steel. The metal was coated by a simple process, the metal being immersed in a phosphating solution based on zinc. Due to the properties of zinc phosphate deposited on the steel surface, especially electrical insulating, the steel coated with this type of layer can be used in explosive atmosphere.
\end{abstract}

\section{Introduction}

The importance of explosion prevention and protection is very high, because the consequences of the explosion can be devastating. During the explosion there are a multitude of risk factors (i.e. flames, projected particles, toxic substances present in the atmosphere etc.), which can lead to loss of human life or health, as well as material loss.

From the point of view of health and safety at work, working in potentially explosive atmospheres is treated with a great seriousness. Therefore, according to the ATEX directive, when the worker carries out his activity in an area where there is a danger of explosion, all work equipment or protective equipment used must be made of materials that have anti-spark properties [2]. In accordance with European Directive 89/391 / EEC, in areas where technical and organizational measures are not enough, the worker must receive personal protective equipment from the employer. For the safety systems and work equipment made of steel to be used in potentially explosive environments without the danger of an explosion, coating the steel with a phosphate layer, which has electroinsulating properties, is a cheap and quick way to solve this problem [3-5].

\footnotetext{
*Corresponding author: costica.bejinariu@yahoo.com
} 
The efficient ignition source and the anticipated effects of an explosion lead to the basic principles of explosion prevention and protection, one of these basic principles being the avoidance of all effective ignition sources [6].

When working equipment, made of steel, are subjected to friction or mechanical shocks, different particles can get loose from the contact surface. The temperature of these particles will be very high, due to the energy absorbed during the separation process of iron oxides from the surface of the equipment. Therefore, in the case that the working atmosphere is in the flammable range, the incandescent particles, i.e. mechanical or frictional sparks, can ignite the combustible vapour/air mixture and produce an explosion. [7]. In dust stored in technical installations, sparks can lead to fiery combustion and this can lead to an explosion. Light metals like titanium or zirconium can also generate sparks when impacted or scratched by sufficiently strong materials, even in the rust absence. If hazards, due to mechanically generated sparks, have been identified, depending on the explosive atmosphere (gases/vapours/mists and/or dust as a flammable substance) a series of requirements specific to the activities carried out in explosive environments must be observed [8].

Mechanical sparks and overheated surfaces may occur as a result of the desired (technical or technological) or unwanted (accidental) interaction between metals, between metals and rocks, or even between rocks. The interaction between solid bodies can be in impact or friction form. Research into processes that generate a mechanical spark or overheated surfaces has shown that striking hit, after tangential trajectories, produces an intense mechanical spark, while continuous friction produces heat that can generate overheated surfaces [9].

Mechanical sparks are metallic or other particles, released from one of the friction surfaces, which are incandescent, either from the initial phase of detachment or as a result of the oxidation process in contact with atmospheric air [10].

Because mechanical sparks are an effective product of rubbing, they are still known in the literature as rubbing particles [11].

The metals friction sparks, under some conditions, are heated to the ignition temperature of the metal particles. In this situation, in a very short time, it is possible to release a heat quantity that is sufficient for heating the combustible gas mixtures volume, which adheres to the particles, up to the ignition temperature [12]. For some metals, heating mechanisms, especially at the initial temperature of the ignition, are influenced by the catalytic properties of the metal particles surface.

The caloric energy of the metal particle is depending on: the temperature which it came off and the metal type. The ignition of the flammable gas mixtures from the mechanical spark from hard oxidizable metals can be analyzed by the intersection of the ignition energy curve of the flammable gas mixture according to the fuel content with the calorific rights of the mechanical particles [10-12].

After heating the critical volume of the fuel gas mixture, at the ignition temperature, the ignition occurs and then the flame spreads throughout the fuel mixture volume.

The article approaches the spark protection problem of material, testing by friction and shock tests the possibility of its use in potentially explosive atmospheres following the deposition of a phosphate layer on the metal surface.

\section{Phosphate coating - spark protection}

The phosphate layer deposited on the surface of the metallic material can improve its antispark properties. Thus, offering the possibility of using the metal in potentially explosive atmospheres [13]. The deposition of phosphate layers based on zinc and manganese was done by immersion on the surface of C45 quality carbon steel. This steel is widely used in various fields due to the low costs of obtaining and manufacturing it [14]. 
It is known that the phosphating process is widely used to facilitate the deposition of new layers (paint, lubricant) and to improve the corrosion resistance of the metal [13].

According to the results obtained from previous tests [16], it was considered that 3 types of tests should be used for the impact test, these being presented in Table 1.

Table 1. Sample types

\begin{tabular}{|c|c|}
\hline SI & Zinc phosphate sample \\
\hline SII & Manganese phosphate sample \\
\hline SIII & Painted zinc phosphate sample \\
\hline
\end{tabular}

The phosphating process included several steps aimed at preparing the material for the deposition of the phosphate layer, as well as its actual deposition by immersion for 30 minutes in the phosphating solution, followed by drying the samples [15].

The phosphating solutions used include phosphoric acid, nitric acid, sodium nitrate, sodium tripolyphosphate, sodium hydroxide, as well as zinc chips (PI sample), respectively manganese and nickel chips (PII sample). In the case of the third sample (PIII) was used as a base layer, the zinc phosphate layer (PI) on the surface of which was deposited by spraying a layer of elastomer-based paint, purchased commercially.

\subsection{The impact test}

The impact test was performed according to STAS 10449-86 and consisted of simulating, on a special stand, the process of forming sparks that may occur as a result of an impact. The impact is simulated between a rusty plate inclined at $35^{\circ}$ and the sample, and the impact energy is determined by the formula:

$$
E=m \cdot g \cdot h \quad[J]
$$

where: $\mathrm{m}$ - falling mass [kg], g- gravitational acceleration $\left[\mathrm{m} / \mathrm{s}^{2}\right]$ and $\mathrm{h}$ - falling height $[\mathrm{m}]$

Three types of samples were used for the impact test: steel sample coated with zinc phosphate layer (PI), steel sample covered with manganese phosphate layer (PII) and steel sample covered with zinc phosphate layer and elastomer-based paint (PIII). The size and shape of these samples are shown in Figure 1, and the assembly method and test stand are shown in Figure 2.
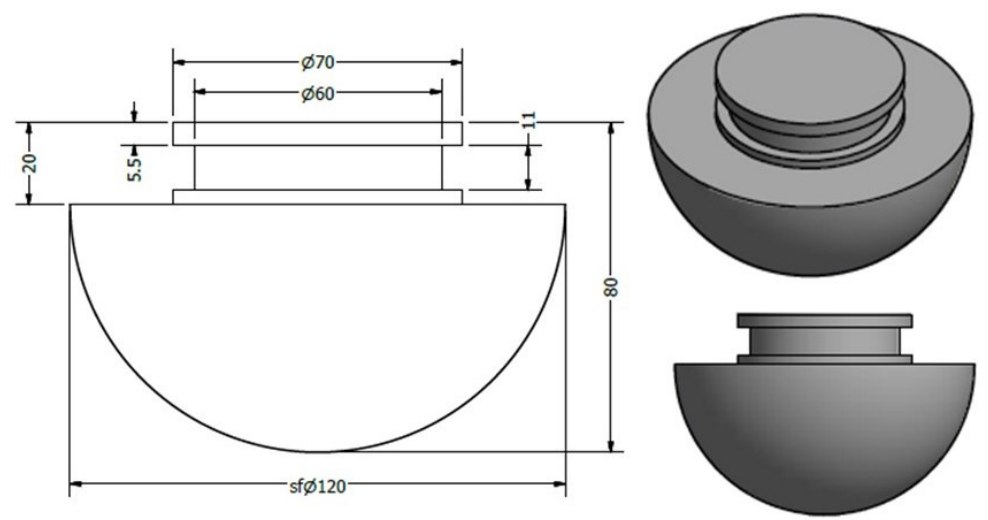

Fig. 1. Schematic representation of the samples used in the impact test 

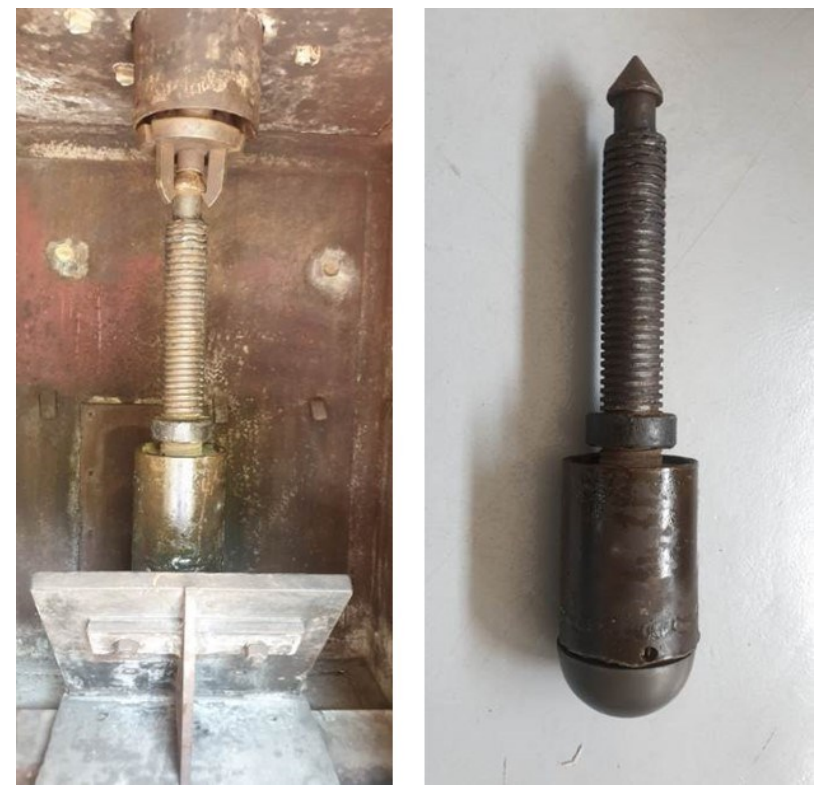

Fig. 2. Representation of the impact test stand and the way of assembling the sample.

For all analysis samples, a number of 10 tests were performed at an impact energy of 92 J. The explosive mixture used consists of air with $10 \% \mathrm{H} 2$.

The results obtained from the impact test for the mentioned samples are presented in Table 2 .

Table 2. Impact test results.

\begin{tabular}{|c|c|c|c|c|c|c|}
\hline \multirow[b]{2}{*}{ Sample } & \multirow[b]{2}{*}{$\begin{array}{c}\text { Impact } \\
\text { energy } \\
{[\mathbf{J}]}\end{array}$} & \multirow[b]{2}{*}{$\begin{array}{c}\text { Number } \\
\text { of } \\
\text { test } \\
\text { (impacts) }\end{array}$} & \multirow[b]{2}{*}{$\begin{array}{c}\text { The } \\
\text { explosive } \\
\text { mixture }\end{array}$} & \multicolumn{3}{|c|}{ Test results } \\
\hline & & & & $\begin{array}{c}\text { Existence of } \\
\text { incendiary } \\
\text { sparks } \\
\text { YES / NO }\end{array}$ & $\begin{array}{c}\text { Ignition of } \\
\text { explosive } \\
\text { mixture } \\
\text { YES / NO }\end{array}$ & $\begin{array}{c}\text { The } \\
\text { appearance of } \\
\text { ignition in } \\
\text { explosive } \\
\text { mixture } \\
\text { enriched with } \\
\text { O }_{2} \text { up to 25\% } \\
\text { (YES / NO) } \\
\end{array}$ \\
\hline 1 & 92 & 10 & \multirow{4}{*}{$\begin{array}{c}10 \% \text { vol. } \\
\text { H2 }\end{array}$} & NO & $\mathrm{NO}$ & NO \\
\hline 2 & 92 & 10 & & NO & NO & NO \\
\hline 3 & 92 & 10 & & NO & $\mathrm{NO}$ & NO \\
\hline 4 & 92 & 10 & & NO & NO & NO \\
\hline
\end{tabular}

Sparks caused by the impact are considered safe if no ignition occurs during the first 10 attempts in the explosive mixture used and if no more than 8 ignitions occur during the next 32 attempts in the explosive mixture enriched with up to $25 \%$ oxygen.

Following the tests, it was observed that both, the samples from steel on the surface of which a phosphate layer was deposited, as well as the phosphate and painted sample did not show sparks at the moment of impact. 


\section{Conclusions}

Following the results of the above tests and taking into account the test conditions, the steel samples coated with a layer of phosphate-based on zinc or manganese, as well as the phosphate and painted ones did not show sparks.

Given this, it was observed that the phosphate layer deposited on carbon steel surface properties not only improves corrosion resistance and wear resistance of steel, but also due to this coating, the steel can be used in a potentially explosive atmosphere.

\section{References}

1. A.A. Pekalski, J.F. Zevenbergen, S.M. Lemkowitz, H.J. Pasman, PROCESS SAF ENVIRON, 83, 1 (2005)

2. ATEX Directive 94/9/EC, Equipment for potentially explosive atmospheres (1994)

3. C. Bejinariu, D.C. Darabont, E.R. Baciu, I. Ionita, M.A.B. Sava, C. Baciu, Environ. Eng. Manag. J., 16 (2017)

4. D.C. Darabont, R.I. Moraru, A.E. Antonov, C. Bejinariu, Qual.-Access Success, 18 (2017).

5. D.C. Darabont, R.I. Moraru, A.E. Antonov, C. Bejinariu, E D P Sciences: Cedex A, 121 (2017)

6. D. Gabor, S.M. Radu, E. Ghicioi, M. Paraian, A.M. Jurca, N. Vatavu, F. Paun, C.M. Popa, Quality - Access to Success, 20 (2019)

7. H.R. Phillips, Identify methods to reduce the risk of explosions and fires caused by frictional ignition hazards. Safety in Mines Research Advisory Committee (1999)

8. B. Lewis, B. Elbe, Combustion, flames and explosions of gazes, (Academic Pres INC New York and London, 1961)

9. A. Jurca, N. Vatavu, S. Sicoi, L. Lupu, F. Paun, Wiertnictwo Nafta Gaz, 26, 4 (2009)

10. Ch. Proust, S. Hawksworth, R. Rogers, M. Beyer, D. Lakic, D. Raveau, P. Herve, V. Pina, C. Petitfrere, X. Lefebvre, Journal of Loss Prevention in the Process Industries, 20, 4-6 (2007)

11. S. Robert, B.Sc.M.A. Silver, The London, Edinburgh, and Dublin Philosophical Magazine and Journal of Science, 23 (1937)

12. A.C. Fernandez-Pello, C. Lautenberger, D. Rich, C. Zak, J. Urban, R. Hadden, S. Scott, S. Fereres, COMBUST SCI TECHNOL, 187 (2015)

13. D.P. Burduhos-Nergis, C. Bejinariu, S.L. Toma, A.C. Tugui, E.R. Baciu, MATEC Web Conf., 305 (2020)

14. C. Bejinariu, D.P. Burduhos-Nergis, N. Cimpoesu, Materials, 14, 1 (2021)

15. D.P. Burduhos-Nergis, P. Vizureanu, A.V. Sandu, C. Bejinariu, Appl. Sci., 10, 8 (2020)

16. D.P. Burduhos-Nergis, P. Vizureanu, A.V. Sandu, C. Bejinariu, Materials, 13, 15 (2020) 